\title{
ESCOLA ATRÁS DAS GRADES: COMO USAR A AVALIAÇÃO A FAVOR DA APRENDIZAGEM NO CONTEXTO PRISIONAL?
}

\section{Carla Poennia Gadelha Soares* Tania Vicente Viana **}

\begin{abstract}
Resumo: O objetivo deste artigo é refletir sobre as concepções discentes a respeito da avaliação da aprendizagem no contexto prisional. A pesquisa foi realizada entre os meses de janeiro e dezembro de 2016, contando com 25 alunas privadas de liberdade, matriculadas na escola que funciona dentro do Presídio Feminino em Itaitinga-Ceará. Os dados foram coletados a partir da aplicação de entrevistas e analisados à luz da Análise do Conteúdo.
\end{abstract}

Palavras-chave: educação; prisão; avaliação da aprendizagem.

Resumen: Este artículo tiene como objetivo reflejar las concepciones de estudiantes con respecto a la valoración de aprendizaje en el ambiente de la prisión. Una investigación fue realizada desde enero a diciembre de 2016, con una muestra de 25 estudiantes privadas de libertad, matriculadas en Bachillerato en un Centro Penitenciario Femenino en Itatinga-Ceará. Se ha realizado un análisis de contenido de los datos recopilados a través de entrevistas.

Palabras claves: educación; prisión; evaluación del aprendizaje.

\section{Considerações Iniciais}

"Mãe, tirei um dez na prova! Me dei bem, tirei um cem e eu quero ver quem me reprova/ Decorei toda lição / Não errei nenhuma questão [...] Quase tudo que aprendi, amanhã eu já esqueci / Decorei, copiei, memorizei, mas não entendi". Esse trecho da música Estudo Errado, de Gabriel, O Pensador, satiriza a atenção excessiva que pais $e$ filhos dedicam às notas escolares. Na verdade, elas são motivos de preocupação não só para as famílias, mas também para a sociedade, em geral, e para as instituições de ensino, em específico (DEMO, 2002, 2004, 2010; LUCKESI, 2001, 2005, 2011, 2014).

\footnotetext{
* Doutora em Educação pela Universidade Federal do Ceará. E-mail: poenniasoares@gmail.com

* Professora Adjunta do Departamento de Fundamentos da Educação da Faculdade de Educação da Universidade Federal do Ceará. Doutora em Educação pela Universidade Federal do Ceará. Endereço eletrônico: taniaviana@secrel.com.br
}

Então, para que servem as notas? $A$ priori, não é necessário nos debruçarmos sobre os resultados de pesquisas empíricas para supormos quais seriam as principais respostas a esse questionamento. Certamente, a maioria diria que elas servem para aprovar ou reprovar, seja no processo seletivo para ingresso na Educação Superior, na entrevista de emprego, ou na escola.

É bem verdade que as notas servem para incluir ou excluir pessoas, como pontuou Garcia (2001). Quantos amigos não tiveram suas vidas transformadas pelo décimo de ponto que tiraram a mais que seu concorrente em uma prova de concurso? Quantos estudantes não se desesperaram por não ingressarem no curso dos sonhos por uma questão errada que lhes baixou a nota? Quantos acadêmicos sofrem devido à dificuldade de entenderem a nota baixa atribuída pela banca de entrevista do mestrado tão

SOARES, Carla Poennia Gadelha; VIANA, Tania Vicente. Escola atrás das grades: Como usar a avaliação a favor da aprendizagem no contexto prisional? Revista Sul-Americana de Filosofia e Educação. Número 32/33: nov. 2019 - out. 2020, p. 4-19. DOI: https://doi.org/10.26512/resafe.v1i32/33.35101 
desejado? Se fosse a nossa intenção, essa lista poderia se multiplicar ad infinitum. No entanto, o que queremos é evidenciar que Vasconcellos (2008, p. 18) tem razão quando diz que há uma lógica muito bem fundamentada para que todos deem à nota demasiada importância, afinal, "[...] no fundo, é ela que decide sua vida".

Essa lógica, porém, traz muitos prejuízos quando nos referimos ao contexto escolar. O maior deles se refere, em nosso entendimento, à falsa ideia de que notas escolares traduzem a qualidade da aprendizagem do aluno. Se essa conjectura fosse verdadeira, poderíamos, de forma simplista $e$ lógica, afirmar que as notas dos alunos representam também a qualidade do trabalho docente.

Sem o objetivo de apontar culpados, nem oferecer receitas, este artigo tem como objetivo refletir sobre as concepções discentes a respeito da avaliação da aprendizagem e discutir possibilidades para encarar os desafios em avaliação da aprendizagem no contexto da escola na prisão.

\section{O cenário da pesquisa: a escola do Presídio} Feminino (PF)

O PF foi inaugurado no dia 22 de agosto de 1974, no antigo prédio do Convento da Congregação do Bom Pastor, na Praça do Liceu, em Fortaleza. No dia 31 de outubro de 2000, o presídio recebeu novo prédio no município de Aquiraz. Foi construído para abrigar 374 internas, todavia, no dia 5 de dezembro de 2016, acomodava 942 mulheres.

Os registros de oferta de escolarização no PF datam de 1986, quando uma aluna do curso de Pedagogia da Universidade Estadual do Ceará (UECE), Jovita Alves Feitosa, desafiou-se a alfabetizar mulheres presidiárias. $\mathrm{O}$ trabalho realizado pela jovem pedagoga chamou a atenção da Secretaria da Educação (Seduc), fazendo com que, em pouco tempo, o ensino no PF passasse a ser motivo de preocupação e investimentos públicos, com a aquisição de materiais didáticos e a seleção de professores (SOARES, 2015).

Em 2009, a Secretaria da Justiça e Cidadania (Sejus), em parceria com a Secretaria da Cultura (Secult), inaugurou nessa penitenciária a Biblioteca Marieta Cals. Inicialmente houve uma doação de 2.000 livros. Em abril de 2014, esse número chegou a 8.216 exemplares, sendo 508 periódicos e 7.708 livros. Segundo dados fornecidos pela Sejus-CE, em janeiro de 2017 a média de retiradas semanais por leitoras era de aproximadamente 300 livros.

No ano de 2013, a Seduc-CE, junto à Faculdade Católica do Ceará (FCC), passou a possibilitar às presidiárias o ingresso na Educação Superior, mediante prova de seleção ao curso de graduação em Filosofia. A primeira turma atendeu a 14 alunas. $\mathrm{O}$ curso será concluído em junho de 2017, com duração de quatro anos. Suas aulas ocorrem três vezes por semana, das 16 às 19 horas, nas instalações da própria penitenciária.

Ainda sobre o tema, destacamos que uma ex-aluna da escola ficou nacionalmente conhecida após ingresso no curso de História na Universidade Federal do Ceará (UFC), por meio do Sistema de Seleção Unificado (Sisu), em 2011. Em 2016, Cíntia concluiu a graduação e agora tem um novo 
sonho: ministrar aulas de História nas salas de aulas dos presídios cearenses.

Durante os anos de 2014 e 2015, sete internas conquistaram vagas em cursos superiores em universidades públicas do $\mathrm{Ce}$ ará, no entanto, por decisão judicial, nenhuma delas foi autorizada a frequentar às aulas. Importante mencionar que o teor da deliberação dos magistrados não foi tornado público. Portanto, desconhecemos as razões apontadas pelos juízes para manter as internas longe dos bancos da universidade.

De nossa parte, compreendemos que o acesso à Educação Superior extramuros é uma excelente ferramenta para ressocialização do detento, por permitir que ele se reintegre à sociedade de modo gradual, por qualificá-lo profissionalmente e por desenvolver novas habilidades cognitivas e sociais. Importante mencionar ainda que o preso, quando autorizado a estudar fora dos limites da prisão, tem que prestar contas mensalmente com o poder judiciário sobre sua frequência e desempenho acadêmico. Além do mais, dependendo da periculosidade do interno, ele poderá frequentar às aulas sob escolta judicial ou sob monitoramento eletrônico por meio do uso da tornozeleira.

O PF conta também, desde 2013, com 80 alunas matriculadas no ProJovem Prisional. Segundo a Resolução no 54, de 21 de novembro de 2012, o programa visa à promoção de ações para a elevação da escolaridade, a qualificação profissional em nível inicial e a participação cidadã dos jovens beneficiários. Além disso, as alunas matriculadas recebem uma bolsa mensal de 100 reais, entregue a algum familiar. As aulas ocorrem no período noturno dentro das salas de aula da penitenciária e são destinadas às pessoas condenadas à prisão em regime fechado, com idade entre 18 e 29 anos, que saibam ler e escrever, mas que não tenham concluído o Ensino Fundamental. Os cursos oferecidos têm duração de 18 meses, com carga horária de 1.200 horas-aula.

No que concerne à Educação Básica, em 2016, 12 alunas estavam matriculadas nos anos iniciais do Ensino Fundamental, 90 nos anos finais do Ensino Fundamental e 60 no Ensino Médio. Com relação à infraestrutura, a penitenciária feminina possui um módulo educacional com cinco salas de aula, dotadas de mobiliário adequado às práticas pedagógicas.

Os dados apontam que em janeiro de $2017,70 \%$ das mulheres recolhidas no $\mathrm{PF}$ respondem pelo crime de tráfico de entorpecentes. A esse respeito, Moura (2005), em dissertação de mestrado intitulada Porta fechada, vida dilacerada - mulher, tráfico de drogas e prisão: estudo realizado no presídio feminino do Ceará, constatou que a maioria desses crimes tem influência afetiva masculina, geralmente dos companheiros ou maridos e, em menor proporção, dos pais ou irmãos. Essa realidade continua se confirmando hodiernamente. No dia das visitas, apenas suas mães as esperam com um sorriso sofrido na face. "Os companheiros? Ah! Esses estão buscando outras para envolverem na vida do crime", disse uma presa deixada pelo marido por ocasião do encarceramento.

\section{Os instrumentos e a amostra da pesquisa}

A pesquisa foi realizada entre os meses de janeiro e dezembro de 2016, contando com 25 alunas privadas de liberdade, 
matriculadas no Ensino Médio da escola que funciona dentro do Presídio Feminino. Visando preservar a identidade dos colaboradores, utilizaremos nome de flores em substituição aos seus verdadeiros nomes.

Os dados empíricos foram coletados a partir da aplicação de entrevistas, que tinham como intuito conhecer as concepções das educandas a respeito da avaliação do ensino-aprendizagem. Para a organização $e$ análise dos dados coletados, utilizamos a técnica da Análise do Conteúdo (AC). Para Franco (2003), a razão da AC é produzir inferências, pois elas conferem à pesquisa relevância teórica. Uma informação unicamente descritiva, que não tenha relação com outros atributos ou com o contexto $e$ as características do emissor, pouco tem a contribuir. Como lembra Bardin (1995), o analista deve saber tirar proveito do tratamento da mensagem que manipula, para inferir (deduzir de maneira lógica) conhecimento sobre o emissor da mensagem ou sobre o seu meio.

\section{Concepções discentes acerca da avaliação da aprendizagem: memórias das experiên- cias extra e intramuros}

Com o objetivo de conhecer as concepções das alunas sobre a avaliação da aprendizagem, recorremos à seguinte pergunta durante a aplicação da entrevista semiestruturada: "De acordo com suas experiências, o que significa avaliação da aprendizagem?". Os relatos das educandas, grosso modo, trazem descrições dramáticas de experiências vividas, representando, destarte, uma concepção de avaliação associada a instrumento de poder e disciplinamento, conforme verificamos nas transcrições adiante.

Avaliar é dar nota para gente; é fazer uma prova valendo uma nota. (Acácia).

A avaliação diz quem passou de ano. [...] Lembro que uma vez só porque esqueci de colocar o nome do professor na prova, ele me deu uma nota baixa. Disse que eu tinha que prestar mais atenção nas coisas (Dália).

Avaliação é a pedra no sapato; é o pesadelo de qualquer aluno. Eu nunca fui muito interessada. (Rosa)

Avaliação é a mesma coisa que prova. Eu nunca tive muita sorte. Eu tinha problema de visão. (Dália).

A avaliação é feita para aprovar e reprovar o aluno. Eu nunca me esqueço da professora que me reprovou por dois décimos em Inglês. Eu até gostava de inglês, mas odiava aquela bruxa (Gardênia).

A avaliação serve para ver se estamos entendendo a matéria. [...] Tem professor que, sinceramente, parece que tem um pacto com o coisa ruim. O professor é bonzinho nas aulas mas, quando vai chegando perto da prova, ele se transforma num carrasco que quer comer nosso fígado. (Girassol).

Lembro que o professor tirava ponto da gente até se a gente olhasse pro lado. Isso era uma avaliação ruim (Orquídea)

Com relação à concepção conferida à avaliação da aprendizagem, $60 \%$ das alunas afirmaram que avaliar é sinônimo de 
provas e notas; $20 \%$ admitiram que a finalidade da avaliação é promover ou reter os educandos em uma etapa da escolaridade; enquanto $20 \%$ asseveraram ser um meio utilizado pelo professor para investigar a aprendizagem dos alunos.

Dentro do ritual pedagógico desvelado pelas alunas, a avaliação escolar serve para "[...] proclamar a homogeneidade pela equidade formal supostamente encontrada nos instrumentos avaliativos; usar de procedimentos que apontam as diferenças individuais, por meio dos quais classifica, premia $e$ pune" (CAMARGO, 1996, p. 168). Praticada nessa perspectiva, Luckesi (2001, 2005, 2011a) afirma que temos a realização de exames escolares sob o viés da pedagogia do exame em detrimento da efetiva prática de uma avaliação comprometida com a aprendizagem do aluno. Nas palavras de Esteban (2013, p. 105):

A avaliação escolar, que mantém a lógica do exame, pode ser entendida como um dos métodos mais suaves, corporalmente menos violentos e visualmente menos perceptíveis, de manter a disciplina; um dos instrumentos capazes de atuar com intensidade $e$ amplitude sobre o sujeito em sua totalidade. Tem o sentido de disciplinar não só o corpo, mas também o pensamento, a vontade, as disposições.

Foucault (2008) acrescenta que, diante da constatação do erro, o aluno é punido por um mecanismo penal que se utiliza de toda uma série de processos perversos $e$ sutis, que podem ir do castigo físico a torturas psicológicas e pequenas humilhações.
Vasconcellos (2008) elenca alguns fatores que embasam a lógica do absurdo, tão presente nos depoimentos das alunas: i) a lógica de os professores montarem um clima de tensão em cima das provas, justificando que assim estarão preparando o aluno para o mundo real que não é nada fácil; ii) a lógica de que a escola não é responsável pelo medo e nervosismo dos discentes, uma vez que a culpa é deles, pois não estão habituados a estudar; iii) a lógica de que a escola precisa valorizar muito a nota, pois, afinal, é necessário manter os alunos motivados. Essa última lógica condiz com a pseudomotivação, que, em lugar de provocar uma autêntica mobilização para a aprendizagem, produz estresse e sofrimento no aluno, o qual passa a trabalhar, quase que exclusivamente, pela nota.

Os relatos das alunas, além de trazerem evidências dessa lógica do absurdo, revelam fortemente a presença de uma violência simbólica, que, segundo Esteban (2013), é menos perceptível que as agressões físicas, dificultando que o sujeito identifique o agressor, o que contribui para que a vítima vá internalizando um forte sentimento de inferioridade e culpa por seu fracasso.

A aluna Orquídea citou um procedimento tratado por Hoffmann (2013, p. 62): a "[...] adição ou subtração de pontos por atitudes dos alunos, arbitrariamente". Consoante a autora, muitas notas são atribuídas seguindo critérios individuais, vagos, confusos ou mesmo precisos demais em determinadas situações. Hoffmann (1991, 1996) conclui que a nota tem sido conferida ao aluno sem um estudo analítico e minucioso sobre o seu real significado e implicação. Depresbiteris (2011, p. 154) complementa 
dizendo que o grande problema "[...] é a crença de que ela imprime maior precisão ao processo avaliativo".

Outros aspectos dúbios referentes ao uso da nota escolar são apontados por Vasconcellos (2004, 2008), que prefere chamálos de perversóes da avaliação. Um deles condiz com a pseudomotivação pela nota, que, em lugar de provocar uma autêntica mobilização para a aprendizagem, provoca no aluno estresse e sofrimento, que passa a trabalhar, quase que exclusivamente, pela nota. A nota alta deve ser atingida a qualquer custo e, nesse processo de busca, podese - de sorte - alcançar a aprendizagem. Essa busca conflui para que os educandos assumam o ofício do aluno que, segundo Perrenoud (1999, p. 151), consiste:

[...] principalmente em desmontar as armadilhas colocadas pelo professor, decodificar suas expectativas, fazer escolhas econômicas durante a preparação e a realização das provas, saber negociar ajuda, correções mais favoráveis ou a anulação de uma prova mal sucedida.

Depreende-se daí que as notas, como vêm sendo praticadas em nossas escolas, passam a desempenhar o papel de prêmio ou de castigo, alienando a relação pedagógica, na medida em que tanto o aluno como o professor passam a trabalhar em função dela (VASCONCELLOS, 2008). Luckesi (2014, p. 17) endossa o pensamento de Vasconcellos (2008) ao dizer que elas, do jeito que estão, "[...] não nos ajudam a realizar o sonho, a esperança e o desejo de democratização do ensino. Ao contrário, camuflam a realidade para que enxerguemos os seus limitados processos e resultados".

As lembranças remontam a experiências vivenciadas nas escolas extramuros. Em função disso, resolvemos indagar às alunas sobre como elas concebiam a avaliação de aprendizagem realizada na escola dentro de um sistema eminentemente repressivo: o cárcere. Fizemos a seguinte pergunta durante a aplicação da entrevista semiestruturada: "Aqui na escola do presídio, como é realizada a sua avaliação da aprendizagem?".

Aqui é tudo tão diferente. Aqui a gente percebe que o professor quer ver o nosso sucesso, sabe? Lá fora, a gente vê muito essa história de professor não gostar de aluno e de aluno não gostar de professor. Como é que se aprende desse jeito? Para aprender, eu acho que você precisa confiar em quem está ensinando. $\mathrm{Eu}$ acredito que essa amizade entre nós e as professoras ajuda muito a gente a aprender aqui dentro. Lá fora, os professores parecem que gostam de dar nota vermelha para a turma, então fazem prova bem difícil só para o aluno cair e se arrebentar todo. Aqui dentro, a gente vê a professora feliz quando a gente consegue fazer uma coisa direito; a gente faz tudo para agradar (Íris).

Apesar do contexto de vigilância da prisão, a escola é percebida pelas alunas como um local capaz de fazê-las experimentar uma sensação de liberdade. As relações estabelecidas no contexto da sala de aula colaboram para que as discentes encontrem novas possibilidades de existência. 
Destarte, frente ao relato de Íris, percebemos que a afetividade contribui positivamente na aprendizagem do conteúdo, uma vez que a forma como as docentes se relacionam com as educandas reflete diretamente nas relações das alunas com o conhecimento. Sendo assim, a responsabilidade do professor não está somente na relação estabelecida com os objetos do conhecimento, mas também com os efeitos dessas experiências vivenciadas em sala de aula e para além dela.

Rosenthal e Jacobson (1981) esclarecem que a expectativa que o professor elabora sobre a aprendizagem do aluno pode interferir de modo significativo no processo de ensino-aprendizagem, de sorte que o comportamento discente seja modelado pela expectativa do educador, e este, por sua vez, responde de acordo com o que ele supõe ser possível ao seu aluno.

Sobre a temática, Tagliaferro (2004, p. 248) confirma que:

A relação sujeito-objeto é marcada pelo entrelaçamento dos aspectos cognitivos e afetivos, ou seja, a futura relação que se estabelece entre o aluno e o objeto do conhecimento (no caso, os conteúdos escolares) não é somente cognitiva, mas também afetiva. Isso mostra a importância das práticas pedagógicas desenvolvidas pelo professor, pois as mesmas estarão mediando a relação que se estabelece entre o aluno $e$ os diversos objetos do conhecimento envolvidos.
As educandas revelam que o convívio harmonioso entre os sujeitos que fazem parte do processo de ensino-aprendizagem contribui significativamente para que se sintam valorizadas, respeitadas e motivadas para estudar. Assim, podemos inferir que o acompanhamento atento e cuidadoso do processo de desenvolvimento das alunas favorece o bom relacionamento delas com o objeto do conhecimento, como se demonstra nos relatos que seguem:

As professoras têm moral com a gente. Elas se interessam por nós, olham a gente nos olhos, escutam a gente, então elas ficam com moral, entende? Tudo o que elas falam a gente escuta, a gente respeita, a gente compreende. A gente se relaciona aqui na sala como se fosse uma família de verdade. Por isso, eu acho que avaliação não nos assusta. Se as professoras estão do nosso lado, nada vai dar errado (Jasmin).

Notamos, assim, que a boa qualidade das relações pode ser a mola propulsora da aprendizagem. Almeida (2003, p. 15) reforça essa ideia quando considera o estudo da afetividade como um "[...] suporte necessário à atuação do professor". Investir nesse tema se reveste de maior importância quando tratamos do contexto da sala de aula no sistema prisional, que se compõe, em sua maioria, de pessoas consumidas pela tristeza e desesperança.

Ottoboni (1984, p. 93) nos dá uma ideia do quanto o respeito para com o aluno privado de liberdade pode ser libertador:

[...] somente quando o preso sente a presença de alguém que lhe oferece uma amizade sincera, 
destas que não exigem compensações ou retorno, é que se inicia o processo de desalojamento das coisas más armazenadas em seu interior $e$ a verdade começa a assumir o seu lugar, restaurando, paulatinamente, a autoconfiança, revitalizando os seus próprios valores. Isso se chama libertação interior.

Prandini (2004, p. 44) defende que "nenhum conteúdo é aprendido pela pessoa sem que seja modelado pelos afetos, pelo sentido que a aprendizagem do conteúdo em questão tem para o sujeito que aprende". Nessa perspectiva, as alunas Alcyone e Vega evidenciam como elas se sentem envolvidas com os conteúdos:

As professoras são show. Elas trazem um pouco de alegria para nossa vida. Às vezes, a gente vem para sala triste e, quando chega aqui, elas dão um sorriso, colocam a gente para cima. [...] Explicam o conteúdo de uma forma divertida, alegre (Girassol).

Antes eu tinha era raiva de professor. Achava que todos eram iguais, que não estavam nem aí para a gente. [...] Aqui dentro eu descobri o verdadeiro significado da prisão e da escola. Eu aprendi que a prisão serve para matar nossa vontade de viver e que a escola serve para trazer a esperança de um dia ter uma vida melhor. Se não fossem as professoras, nem sei o que seria de mim. Hoje, eu me sinto mais preparada para a vida lá fora, para arrumar um emprego (Magnólia).

Para Mello (1987, p. 77), os alunos presos, assim como as camadas populares, veem a Educação como "formas de melhorar de vida, pela possibilidade que nela distinguem de obterem melhor emprego e de participarem da cultura letrada". Essa expectativa é ainda maior nos homens encarcerados, pois, além de pobres, são presos.

Em definitivo, os dados sinalizaram que a motivação para a aprendizagem é resultado da qualidade do encontro entre professoras e alunas. Com base nessa premissa, somos desafiados a formular novas práticas de avaliação, comprometidas com os mesmos objetivos da Educação, quais sejam: o desenvolvimento da autonomia, do senso de solidariedade, da tolerância e a reflexão crítica por parte dos educandos privados de liberdade, permitindo, assim, que eles construam novas possibilidades para o enfrentamento dos desafios que a vida lhes oferece. Nesse sentido, o professor precisa ser aquele que, "[...] amorosamente, acolhe, nutre, sustenta e confronta sua experiência, seus anseios e caminhos, para que o outro construa sua trajetória pessoal enquanto aprende e se desenvolve" (LUCKESI, 2011a, p. 134).

Essa discussão será sempre inconclusa, apesar de imensamente necessária, considerando as diversas óticas pelas quais pode ser abordada. Em vista disso, no lugar de prosseguir com as considerações acerca dos usos e abusos das notas escolares, propomos dar ênfase, na próxima seção, às reflexões sobre um novo questionamento: como podemos usar os registros escolares a favor da aprendizagem? Afinal, estamos de acordo com Luckesi (2014, p. 117) quando assinala que "[...] o que importa é a busca da melhor solução, nunca a lamentação dos problemas e dificuldades". Assim, os obstáculos não devem ser fontes para o desânimo 
e para a desesperança, mas, sim, desafios que nos convidam a investir cada vez mais numa avaliação que contribua, efetivamente, para a formação plena de nossos educandos.

\section{O uso de comentários e rubricas: registros escolares a favor da aprendizagem no con- texto prisional}

Nossa memória parece pequena diante de tantos eventos importantes de nossas vidas. A riqueza dos detalhes de momentos marcantes para nós vão se perdendo no passado, embora não queiramos esquecê-los jamais. A verdade é que o avanço das tecnologias nos auxilia no objetivo de arquivar, com mais segurança, episódios que queremos lembrar para sempre. O som do primeiro choro de um filho, a leitura do texto na festinha do colégio, os flashes dos convidados na formatura, o sorriso de um amigo no reencontro, o abraço apertado na mãe, essas emoções podem ser revividas sempre que ouvirmos um áudio, visualizarmos um vídeo ou uma fotografia. Sem esses recursos, provavelmente, teríamos mais dificuldade para recordar os detalhes do contexto que embalaram cada uma dessas cenas.

Registrar implica "colocar na memória, na lembrança" (HOUAISS et al., 2009); significa "tomar nota, assentar o dito para não olvidá-lo ou para servir de argumento quando necessário for" (PRIBERAM, 2013). Registrar, por conseguinte, é importante no caminho da vida, o que não deve ser diferente no âmbito escolar, porque, na verdade, como diz Dewey (1978, p. 37), uma não se separa da outra, a "educação é vida".

A memória escolar, nessa esteira, constitui-se de registros feitos: i) pelos profes- sores, quando eternizam as notas nos boletins, a frequência nos diários escolares, as anotações nos trabalhos; ii) pelas equipes diretivas, quando registram ocorrências de mau comportamento nas fichas individuais dos educandos; iii) pelas famílias, quando firmam compromisso com a escola no ato da matrícula, em reuniões e demais eventos. Além desses registros, tidos como oficiais, têm-se ainda as fotos e os vídeos de outros momentos, não menos importantes, mas, de certo modo, menos valorizados pelas instituições de ensino.

Embora a LDBEN (Lei no 9.394, de 20 de dezembro de 1996), no art. 26 do capítulo II - Da Educação Básica -, reconheça que "os currículos [...] devem ter uma base nacional comum a ser complementada por uma parte diversificada, exigida pelas características regionais e locais da sociedade, da cultura, da economia e da clientela" (grifo nosso), os registros escolares que constam nos boletins, históricos ou diplomas não reservam espaços para observações sobre as atividades que compõem essa parte diversificada do currículo. Ousamos perguntar se alguém já viu, em algum desses documentos, registros como "o aluno participou do projeto de dança na escola X", "a aluna colaborou na realização de estudos cooperativos com os colegas de turma", "o discente apresentou trabalho na Mostra Cultural?" Certamente não!

Em nosso entendimento, a memória escolar tem se resumido apenas ao registro do rendimento escolar conseguido pelo aluno ano após ano, eternizado por meio da nota. De forma mais específica, o que vale na escola é batalhar pela aprovação, num embate no qual professor e aluno estão, 
quase sempre, em lados opostos; no qual os colegas de sala se percebem como concorrentes, que tudo fazem para merecer a honra de um elogio ou de um prêmio.

Luckesi (2014, p. 103) define o registro escolar como sendo "[...] a memória do testemunho do educador de que o educando foi acompanhado por ele no ensino $e$ na aprendizagem, num determinado período letivo". Zabalza (2004) complementa que esses registros permitem que façamos uma radiografia da docência, pois, ao apresentarem as evidências de aprendizagens dos alunos, expõem e desnudam o trabalho do educador. Lamentavelmente, é mais comum nos depararmos com queixas embasadas em supostos problemas de aprendizagem dos alunos do que com professores que assumem sua responsabilidade na tarefa de ensinar.

Luckesi (2011b, p. 157), referindose às notas como registros formais da aprendizagem do educando, metaforicamente reflete sobre sua relevância:

existe uma frase que diz assim: 'o mapa não é o território', ou seja, o mapa é uma representação da realidade, e não a realidade mesma no seu pleno modo de ser. De fato, a realidade mapeada sempre é maior e mais complexa que o mapa. Todavia isso não retira do mapa sua capacidade e qualidade na orientação dos que o utilizam para locomoverse no espaço, seja de uma cidade ou de um território qualquer, ou ainda, em nosso caso, de um campo de conhecimentos.

Ainda a respeito dos registros escolares, Demo (2010a, 2010b) argumenta que se o sistema escolar, em geral, opera com números para se referir à aprendizagem discente, nada mais coerente que aprendermos a lidar com eles. Nesse sentido, Demo (2010a, p. 53) sinaliza que "a nota em si não tem culpa. É a cabeça do professor ou do pedagogo que a faz abjeta".

Assim sendo, o autor aponta que a nota, dependendo do tratamento que receba, pode ser a melhor forma de registro da aprendizagem, considerando-se vista as seguintes razões: i) permite visualizar melhor onde o educando está e para onde precisa ir, além disso, seu reducionismo pode ser compensado pela sinalização em torno do que deve ser feito; ii) é mais clara que outros artifícios, no entanto, é mais delicada e, por isso, "[...] exige elegância na sua condução" (Demo, 2010a, p. 26); iii) permite acompanhamentos mais meticulosos do que, por exemplo, comentários genéricos, sugestões suaves, insinuações preliminares, sendo possível, inclusive, elaborar gráficos do desempenho do aluno tendo em vista perceber claramente a sua evolução ou sua estagnação; iv) pode ser mais útil quanto menos for mistificada, mantendo estrita cautela frente a suas limitações.

O sociólogo assinala ainda que a nota não pode ser definitiva, ao contrário, deve sempre considerar a possibilidade de ser discutida e refeita, além de não dever ser usada pelo professor para mostrar sua autoridade, mas para declarar seu compromisso com a aprendizagem do educando e permitir a este que seja cobrado nessa direção. Dentre as propostas do autor, destacamos a que defende que a nota sempre deve ser oferecida ao aluno acompanhada de comentários indicativos de novas rotas a serem percorri- 
das no caminho do conhecimento. A esse respeito, o autor aventa que:

[...] a nota seca é praticamente inútil, porque se assemelha a um tiro, não a uma avaliação justificada. Certamente, quando se trata de nota máxima ou coisa parecida, talvez não seja necessário justificar. Mas, em notas baixas ou muito baixas, se o compromisso for com a aprendizagem, os comentários explicativos e as sugestões de correção passam a ser o mais importante. A nota assume, então, seu verdadeiro e modesto lugar: expressão quantitativa indireta de fenômeno complexo. De um lado, a nota contribui para a riqueza dos comentários e sugestões, à medida que puder ser expressão compacta (ainda que reducionista) deles; de outro, a nota não os esgota, apenas os sinaliza, de modo indireto. (DEMO, 2010a, p. 52).

A partir disso, Demo (2010a, p. 53) deduz que a "a nota torna-se mais real, à medida que não permanecer mera nota", mas que for cercada dos cuidados docentes, intentando aproximá-la ao máximo dos indicativos complexos da aprendizagem. Nesse sentido, a nota deve ser oferecida aos educandos com zelo e segurança para que eles passem a percebê-la como um registro do compromisso com a aprendizagem. O professor, pelo uso da nota, "[...] em vez de pisar no aluno, abre-lhe horizontes, bem desenhados, também porque bem diagnosticados" (DEMO, 2010a, p. 77).
Nessa esteira, a nota passa a ser o reflexo de um cuidado contínuo e exigente por parte do professor com relação ao complexo processo de ensino-aprendizagem, tendo em vista que não apenas o educando deve ser avaliado, mas também a capacidade docente de contribuir com a formação plena do aprendiz.

A nota, nesse enfoque, precisa ser subsidiada por uma convivência constante e zelosa entre alunos e professores; por uma observação meticulosa e permanente direcionada aos avanços e declínios discentes; por um conjunto de comentários detalhados sobre fatos da aprendizagem; por um diálogo claro, sincero e cuidadoso entre educando e educador; e, sobretudo, pela certeza de que todos podem e devem aprender. Somente nesse contexto, a nota adquire condição qualitativa e pode tornar-se um instrumento mais manejável em avaliação (DEMO, 2004, 2010a).

Depresbiteris (2011, p. 157) também oferece importantes contribuições para aprimorar o uso da nota no contexto escolar, quando sugere a elaboração de rubricas. Segundo a autora, as rubricas são "instrumentos de medida pelo qual se estabelecem critérios e ponderações por níveis, com a utilização de escalas. As escalas são estabelecidas de modo a determinar graus de qualidade do que está sendo avaliado".

As provas de Redação de milhões de pessoas que se submetem ao ENEM são avaliadas tendo como parâmetros as rubricas previamente elaboradas por especialistas na área de Avaliação Educacional. Na tabela a seguir, exemplificamos como isso ocorre. 
Tabela 1 - Exemplo de rubrica da Redação do ENEM

\begin{tabular}{c|c}
\multicolumn{2}{c}{$\begin{array}{c}\text { COMPETÊNCIA III: } \\
\text { nemonstrar conhecimento dos mecanismos linguísticos } \\
\text { necessários para a construção da argumentação }\end{array}$} \\
\hline $\begin{array}{c}\text { Nível / Pontua- } \\
\text { ção }\end{array}$ & \multicolumn{1}{c}{ Desempenho expresso pelo participante } \\
\hline $\begin{array}{c}\text { Nível 0 } \\
\text { (0 ponto })\end{array}$ & Não articula as informações. \\
\hline $\begin{array}{c}\text { Nível I } \\
\text { (40 pontos })\end{array}$ & Articula as partes do texto de forma precária. \\
\hline $\begin{array}{c}\text { Nível II } \\
\text { (80 pontos })\end{array}$ & $\begin{array}{l}\text { Articula as partes do texto, de forma insuficiente, com } \\
\text { muitas inadequações e apresenta repertório limitado de } \\
\text { recursos coesivos. }\end{array}$ \\
\hline $\begin{array}{c}\text { Nível III } \\
\text { (120 pontos })\end{array}$ & $\begin{array}{l}\text { Articula as partes do texto, de forma mediana, com ina- } \\
\text { dequações, e apresenta repertório pouco diversificado de } \\
\text { recursos coesivos. }\end{array}$ \\
\hline $\begin{array}{c}\text { Nível IV } \\
\text { (160 pontos })\end{array}$ & $\begin{array}{l}\text { Articula as partes do texto com poucas inadequações e } \\
\text { apresenta repertório diversificado de recursos coesivos. }\end{array}$ \\
\hline $\begin{array}{c}\text { Nível V } \\
\text { (200 pontos })\end{array}$ & $\begin{array}{l}\text { Articula bem as partes do texto e apresenta repertório } \\
\text { diversificado de recursos coesivos. }\end{array}$ \\
\hline
\end{tabular}

Fonte: Guia do Participante - Redação do ENEM (2016).

Tomando por exemplo a rubrica acima, o avaliador pode determinar os níveis da qualidade da aprendizagem do candidato com relação a uma competência específica, nesse caso: a de demonstrar conhecimento dos mecanismos linguísticos necessários para a construção da argumentação. Nessa direção, quanto mais se aproximar da competência esperada, maior será seu nível de entendimento $e$, consequentemente, mais alta será a sua nota - que, nesse exemplo, pode variar de 0 a 200 pontos.

Cabe ressaltar que as rubricas para a avaliação das redações do ENEM foram divulgadas pelo Instituto Nacional de Estudos e Pesquisas Educacionais Anísio Teixeira (INEP), pela primeira vez, apenas no ano de 2012, com o objetivo de esclarecer aos participantes os critérios de avaliação adotados.
Referindo-se às avaliações realizadas em sala de aula, Luckesi (2011a, p. 410) ressalta a importância de os professores divulgarem, previamente, os critérios de avaliação que, segundo o autor, servem para "[...] definir o que queremos como resultado de nossas atividades e, desse modo, estabelecer direção tanto para o ato de ensinar quanto para o de avaliar". Essa recomendação, a nosso ver, estende-se também às avaliações externas, como o ENEM, por exemplo.

Nesse sentido, as rubricas veiculam as expectativas que se têm das habilidades que o aluno deve construir e, segundo Depresbiteris (2011, p. 158), favorecem a atribuição de notas "[...] de forma clara, honesta e rica em informação para o aluno", que consegue facilmente perceber onde está $e$ aonde precisa chegar para atingir uma 
aprendizagem satisfatória em um conteúdo pré-definido.

Porto (2009) amplia essa discussão ao apontar para três diretrizes que devem orientar o trabalho com a rubrica, quais sejam: i) deve ser feita com base na natureza da tarefa que se pretende avaliar; ii) precisa descrever níveis detalhados de desempenho, de competências, na realização de tarefas específicas; iii) devem ter claras as expectativas de desempenho.

A rubrica requer dedicação por parte do professor, que deve planejar criteriosamente o ensino $e$ acompanhar minuciosa $e$ permanentemente a aprendizagem dos educandos. Depresbiteris (2011) lembra que a rubrica requisita cuidados em sua elaboração, tendo em vista detalhar de forma sucinta e clara os objetivos ou competências que devem ser alcançados pelos alunos após o ensino.

Depois de tratamento cuidadoso, as rubricas possibilitam ao docente identificar, de modo mais rápido, se os objetivos predeterminados foram alcançados ou não pelos educandos, favorecendo, consequentemente, a qualidade da ação pedagógica. Depresbiteris (2011) reflete sobre as principais vantagens dessa forma de registro, dentre as quais destacamos o fato de tornar o processo de atribuição de notas mais significativo, justo e confiável; permitir que os processos de avaliação sejam mais harmônicos, mesmo se aplicados por professores diferentes; propiciar que os próprios alunos avaliem seus conhecimentos com base nas rubricas; $e$ permitir que os discentes entendam melhor a qualificação que lhes está sendo atribuída $e$, com base nisso, possibilitar aos alunos me- lhorar o seu desempenho, uma vez que passam a saber onde devem focar seus esforços.

\section{Considerações finais}

Separar os fios que compõem a tessitura dos discursos desvelados ao longo desta investigação consiste em tarefa complexa, haja vista as inesgotáveis possibilidades de análises que podem emergir das experiências de cada leitor. Nesse sentido, este estudo não se propõe a declarar verdades absolutas, mas, sim, lançar reflexões sobre novas incertezas acerca do tema em foco, com a finalidade de abrir perspectivas para outras investigações sobre a avaliação de aprendizagem no contexto do cárcere.

Nessa direção, no momento dedicado às considerações finais do trabalho, importa avaliarmos até que ponto o objetivo do artigo foi alcançado: refletir sobre as concepções discentes a respeito da avaliação da aprendizagem $e$ discutir possibilidades para encarar os desafios em avaliação da aprendizagem no contexto da escola na prisão.

As educandas, no momento de conceituarem a avaliação da aprendizagem, trouxeram lembranças de momentos dolorosos nos quais foram vítimas do uso abusivo $e$ equivocado dos instrumentos de coleta de dados. Suas concepções, nesse sentido, associaram a avaliação a um instrumento de poder e disciplinamento. Quando convidadas a definir a avaliação segundo a experiência na escola dentro do cárcere, os pontos de vista foram diferentes. Elas revelaram que sentem que a avaliação realizada pelas docentes no contexto intramuros está realmente preocupada com a qualidade de sua aprendizagem. 
Oferecemos como sugestão aos docentes que lidam tanto com a realidade intra quanto extramuros o uso dos comentários, propostos por Demo (2010a) e das rubricas, aventadas por Depresbiteris (2011). Quer opte por um ou por outro registro, é certo que devemos estar cientes de que o nosso compromisso como educadores é com a aprendizagem dos alunos. Sem dúvida, são muitos os percalços que nos dificultam qualificar a avaliação do ensino-aprendizagem baixos salários, salas superlotadas, formação docente frágil -, não obstante, temos que lutar para tornar real o que ainda não é possível. Isso faz parte da tarefa histórica de redesenhar e construir o mundo.

Uma mudança na avaliação implica uma mudança mais ampla e profunda na escola; na construção conjunta de novas práticas; na conscientização dos sujeitos de que se avalia para promover a aprendizagem, e não para medi-la. Nesse sentido, no lugar de investir energias em reflexões sobre "que nota atribuir", "como avaliar?", interes- sa refletir sobre "como o professor pode auxiliar o aluno no desafio de aprender cada vez mais?" ou "de posse do conhecimento, como os educandos podem transformar suas vidas e a sociedade?". Assim, sem dúvida, estaremos nos aproximando do verdadeiro sentido da avaliação da aprendizagem: subsidiar o desenvolvimento do aprendiz no caminho de sua trajetória existencial, ajudando-lhe a intervir na realidade e, sobretudo, a superá-la.

Por fim, é fundamental que os atores que atuam nas unidades prisionais se questionem de que maneira a Educação pode contribuir para modificar a prisão e o encarcerado. Assim, pensar na avaliação escolar voltada para pessoas privadas de liberdade implica, nesse sentido, refletir sobre sua contribuição para a vida dos aprisionados e da sociedade em geral, por meio da aprendizagem participativa e da convivência baseada na valorização e desenvolvimento do outro $e$ de si mesmo.

\section{Referências}

ALMEIDA, Ana Rita Silva. A emoção na sala de aula. São Paulo: Papirus, 2003.

CAMARGO, Alzira Leite. O discurso sobre a avaliação escolar do ponto de vista do aluno. 1996. 362 fls. Tese (Doutorado em Educação) - Universidade Estadual de Campinas, São Paulo, 1996.

DEMO, Pedro. Mitologias da avaliação: de como ignorar, em vez de enfrentar problemas. Campinas, SP: Autores associados, 2010a.

DEMO, Pedro. Avaliação qualitativa. Campinas, SP: Autores associados, 2010b.

DEMO, Pedro. Complexidade e aprendizagem: a dinâmica não linear do conhecimento. São Paulo; Atlas, 2002.

DEMO, Pedro. Universidade, aprendizagem e avaliação: horizontes reconstrutivos. Porto Alegre: Mediação. 2004. 
DEPRESBITERIS, Lea. Avaliação da aprendizagem: casos comentados. Pinhais: Editora Melo, 2011.

DEWEY, John. Vida e educação. Tradução de Anísio S. Teixeira. São Paulo: Melhoramentos. Fundação Nacional de Material Escolar. 1978.

ESTEBAN, Maria Tereza. O que sabe quem erra? Reflexões sobre avaliação e fracasso escolar. Petrópolis, RJ: De Petrus et Alii, 2013.

FOUCAULT, Michael. Vigiar e punir: nascimento da prisão. Tradução de Raquel Ramalhete. Rio de Janeiro: Vozes, 2008.

FRANCO, Maria Laura. Análise de conteúdo. Brasília: Plano, 2003. 72 p.

GARCIA, Regina Leite. A avaliação e suas implicações no fracasso/sucesso. In ESTEBAN, Maria Tereza. (org.) et al. Avaliação: uma prática em busca de novos sentidos. Rio de Janeiro: DP\&A, 2001, p. $29-49$.

HOFFMANN, Jussara. Avaliação: mito \& desafio: Uma perspectiva construtivista. Porto Alegre: Mediação, 1991.

HOFFMANN, Jussara Pontos e contrapontos: do pensar em agir em avaliação. Porto Alegre: Mediação, 1996.

HOFFMANN, Jussara Avaliação: Mito \& Desafio: Uma perspectiva construtivista. Porto Alegre: Mediação, 2013.

HOUAISS, Antonio. Dicionário Houaiss da língua portuguesa. Rio de Janeiro: Objetiva, 2009.

LUCKESI, Carlos Cipriano. Avaliação da aprendizagem escolar. São Paulo: Cortez, 2001.

LUCKESI, Carlos Cipriano. Avaliação da aprendizagem na escola: reelaborando conceitos e recriando a prática. Salvador: Malabares, 2005.

LUCKESI, Carlos Cipriano. Avaliação da aprendizagem: componente do ato pedagógico. São Paulo: Cortez, 2011a.

LUCKESI, Carlos Cipriano. Avaliação da aprendizagem escolar: estudos e proposições. São Paulo: Cortez, 2011b.

LUCKESI, Carlos Cipriano. Sobre notas escolares: distorções e possibilidades. São Paulo: Cortez, 2014.

MELLO, Guiomar Namo de. Educação escolar: paixão, pensamento e prática. São Paulo: Cortez, 1987.

MOURA, Maria Jurena de. Porta fechada, vida dilacera - mulher, tráfico de drogas e prisão: estudo realizado no presídio feminino do Ceará. 2005. 145 f. Dissertação (Mestrado em Políticas Públicas e Sociedade) - Universidade Estadual do Ceará, Fortaleza, 2005.

OTTOBONI, Mario. A comunidade e a execução da pena. Aparecida: Santuário, 1984.

PERRENOUD, Philippe. Avaliação: da excelência à regulação das aprendizagens - entre duas lógicas. Porto Alegre: Artmed, 1999. 
PRANDINI, Regina Célia Almeida Rêgo. A constituição da pessoa: Integração funcional. In: MAHONEY, Abigail Alvarenga; ALMEIDA, Laurinda Ramalho de (org.) A constituição da pessoa na proposta de Henry Wallon. São Paulo: Loyola, 2004.

PRIBERAM. Dicionário de língua portuguesa. Disponível em: <www.priberam.pt>. Acesso em: 10 ago. 2016.

ROSENTHAL, Robert.; JACOBSON, Lenore. Profecias autorrealizadoras na sala de aula: as expectativas dos professores como determinantes não intencionais da capacidade intencional dos alunos. In: PATTO, M. H. S. Introdução à psicologia escolar. São Paulo, T. A. Queiroz, 1981.

SOARES, Carla Poennia Gadelha. Primeira escola prisional do Ceará: a avaliação da aprendizagem dos alunos privados de liberdade. 2015. 258 f. Dissertação (Mestrado em Educação) Universidade Federal do Ceará, Programa de Pós-Graduação em Educação Brasileira, Universidade Federal do Ceará, Fortaleza, 2015.

TAGLIAFERRO, Ariane Roberta. Meu professor inesquecível: a construção de uma memória coletiva. Trabalho de Conclusão do Curso de graduação em Pedagogia. São Paulo: Unicamp, 2004.

VASCONCELLOS, Celso dos Santos. Avaliação: Superação da Lógica Classificatória e Excludente: do "é proibido reprovar" ao é preciso garantir a aprendizagem. São Paulo: Libertad, 2004.

VASCONCELLOS, Celso dos Santos. Avaliação: concepção dialética-libertadora do processo de avaliação escolar. São Paulo: Libertad, 2008.

ZABALZA, Miguel Ángel. Diários de aula: um instrumento de pesquisa e desenvolvimento profissional. Porto Alegre: Artmed, 2004.

Recebido em: 10/05/2017 Aprovado em: 17/10/2020 